\title{
Nursing Personnel Perception and Readiness toward Role of Triage Nurse in Emergency Department
}

\author{
Hala Mohammed Mohammed Hassan ${ }^{1}$, Nermin Mohamed Hessin Eid ${ }^{2}$, \\ Aya Ghoneimy Hassanin ${ }^{3}$ \\ ${ }^{1}$ B.Sc. Nursing Science, ${ }^{2}$ Professor of Nursing Administration, Faculty of Nursing, Menoufia \\ University, ${ }^{3}$ Assistant Professor of Nursing Administration, Faculty of Nursing, Benha \\ University.
}

\begin{abstract}
Triage is an autonomous nursing role and essential to patient safety and the efficient delivery of emergency care. Purpose of the study was to identify nursing personnel perception and readiness toward role of triage nurse in emergency department. A descriptive design was utilized to meet the purpose of this study. The sample included was simple random sample of staff nurses; their number was 162 staff nurses and all head nurses working at emergency departments and Critical Care Units at Benha University Hospital. Two instruments for data collection: namely; nursing personnel perception questionnaire and nursing personnel readiness questionnaire. The results and conclusion showed that most of both head nurses and staff nurses had a high perception level toward role of triage nurse in emergency department, all head nurse had a high readiness level and the majority of staff nurses had a high readiness level and there was a highly statistically positive correlation between nursing personnel perception and readiness toward role of triage nurse in emergency department ( $\mathrm{p} \leq \mathrm{o} .001)$. The study recommended; nursing personnel in Benha were in need of education programs about role of triage nurses in emergency department.
\end{abstract}

Keywords: Nursing personnel - Perception - Readiness -Role of triage nurse - Emergency department.

\section{Introduction}

Emergency nursing is a specialty within the field of professional nursing focusing on the care of patients with medical emergencies, that is, those who require prompt medical attention to avoid long term disability or death. Emergency nurses are most frequently employed in hospital emergency departments, although they may also work in urgent care centers, sports arenas, and on medical transport helicopters and ambulances (Welch, 2011).

Emergency department is a very important lifesaving department where the clients admitted under emergency conditions are treated well.It is a 24 hours service, where the nurse is an important member of emergency team. she/he helps the patient admitted to position , assesses the actual and potential problems, provides care as per priority and need ,she/ he uses her knowledge and skill to provide comfort to the patient, she/ he assesses ,monitors ,carries the treatment orders, recognizes the early signs and symptoms and informs to concerned physician in time. In addition, she ensures that patient receives prompt and quality care (Hirni, 2013).

The word triage comes from the French word"e trier", meaning to sort.In the daily routine of the emergency department, triage is to sort patients into groups, based on the severity of their health problems and the immediacy with which these problems must be treated. It may result in determining the order and priority of emergency treatment, the order and priority of emergency transport, or the transport destination for the patient (Chipman, 2017). 


\section{Nursing Personnel Perception and Readiness toward Role of Triage Nurse in Emergency Department}

Triage nursing have been investigated by several nurse researchers, however, most have not clearly articulated a theoretical or conceptual frame work. Many nursing theories do not fit this description and should therefore, in the opinion of the authors, be thought of as models. The recognition primed decision (RPD) model is based on research about decision making under certain conditions such as time pressure, limited time available, high stakes, and changing cues. The authors propose that the (RPD) model can serve as a foundation for research that seeks to understand decision making by triage nurses with the aim of yielding new knowledge that is useful for their practice (Elhabashy,2015).

Rapid and accurate triage requires an emergency nurse with the right qualification, education, and experience. The following qualifications for any nurse :registered nurse, complete a standardized triage education course that includes certified in cardiopulmonary resuscitation and advanced cardiac life support ,emergency nursing pediatric course verification ,trauma nursing core course verification, geriatric emergency nurse education verification, certified emergency nurse certification or certified pediatric emergency nurse, effective communication skills and ability to work collaboratively, Ability to use the nursing process effectively, flexible personality and adaptable to change (Sheehy,2012).

Triage method can try and provide the practitioner with the diagnosis, with the disposal or with a clinical priority. The triage group quickly decided that the triage methodology should be designed to allocate a clinical priority. This decision was based on three major tenets; Firstly, the aim of the triage encounter in an emergency department is to aid both clinical management of the individual patient and departmental management,
Secondly, the length of the triage encounter is such that any attempts to accurately diagnose a patient are doomed to fail, Finally, it is apparent that diagnosis is not accurately linked to clinical priority (Mackway, 2015).

Becoming a triage nurse requires lots of experience in dealing with sick and injured patients, and those who work in this field must be able to assess the patient's condition and determine their need for immediate medical care. Those who are interested in working as a triage nurse must go through a process in order to earn their certification and work in the field of triage nursing. To becoming a triage nurse apply for nursing school, Take all of the requirements needed to get into the nursing program, develop your work experience as a registered nurse, take and pass the emergency nursing triage program (Mohsen,2015).

Emergency nursing is a specialty in which the nurse cares for patients in the emergency or critical phase of their illness or injury, focusing on the level of severity and time critical interventions. Whilst lab orating with members of the emergency team, the emergency nurse plays a crucial role in the identification and care of patients with medical, surgical and injury related emergencies. The emergency nurse identifies life threatening problems, prioritizes the care, carries out resuscitative measures with appropriate management and provides information and emotional support to the patient and his/her family within a supportive health care environment (Elhabashy,2015).

\section{Purpose of the study}

The present study aimed to identify nursing personnel perception and readiness toward role of triage nurse in emergency department at Benha University hospitals. 


\section{Nursing Personnel Perception and Readiness toward Role of Triage Nurse in Emergency Department}

\section{Research Questions}

a) What is the nursing personnel perception toward role of triage nursing?

b) What is the nursing personnel readiness toward role of triage nursing?

\section{Methods}

\section{Design:}

Descriptive study was utilized to conduct this study.

\section{Setting:}

The study was conducted in critical units and selected departments at Benha University Hospitals.

\section{Sampling}

It included all the available head nurses with at least one year of experience and staff nurses who are working at critical units in the above mentioned study setting with at least two year of experience.

\section{Instruments of data collection:}

Data of the present study was collected by using two tools:

The first instrument: Nursing personnel perception questionnaire: It was developed by (Khalil, 2014) and modified by the investigator based on reviewing the related literature (Murry, 2012-kevin, 2013, and peter, 2014). It consisted of two parts:

- Part 1: Included personal characteristics about study subjects as (Sex, age, marital status, educational qualification, years of experience)

- Part 2: Included questions underling items to assess nursing personnel perception toward role of triage nurse in emergency departments. It included
47 items divided under five main categories as following:

\begin{tabular}{|l|c|}
\hline \multicolumn{1}{|c|}{ perception domains } & $\begin{array}{c}\text { Number } \\
\text { of Items }\end{array}$ \\
\hline $\begin{array}{l}\text { Role of triage nurse in emergency } \\
\text { patient assessment. }\end{array}$ & (9Items) \\
\hline Clinical decision making. & (3items) \\
\hline Triage intervention. & $(19$ items) \\
\hline Leadership and management activities. & $\begin{array}{c}(13 \\
\text { items })\end{array}$ \\
\hline Triage nurses prepared qualification. & (3items) \\
\hline
\end{tabular}

The second instrument: Nursing personnel readiness questionnaire

It was developed by the researcher after reviewing the related Literature as (Little, 2014, Giady, 2014, Windy, 2016, Solheim, 2016, Chipman, 2017).

It was used to assess nursing personnel readiness for role of triage nurse in emergency department included 43 items these items divided under two categories as following:

\begin{tabular}{|l|c|}
\hline \multicolumn{1}{|c|}{ Readiness domains } & Numbers of items \\
\hline $\begin{array}{l}\text { Skills that triage nurse must } \\
\text { possess. }\end{array}$ & 25 item \\
\hline $\begin{array}{l}\text { Actions that taken by triage } \\
\text { nurse. }\end{array}$ & 18 item \\
\hline
\end{tabular}

\section{Reliability of tool}

- Reliability of nursing personnel perception questionnaire was measured by using Cronbach's Alpha and the value was (o.85).

- Reliability of nursing personnel readiness questionnaire was measured by using Cronbach's Alpha and the value was (o.83).

\section{Pilot study}

A Pilot study was conducted in June 2017 to assess tool clarity and applicability. It has also served in estimating the time needed for filling the form. The study was tested on $10 \%$ of total subjects, it was done on 17 staff nurses. Some modifications and clarifications for some statements related 


\section{Nursing Personnel Perception and Readiness toward Role of Triage Nurse in Emergency Department}

to their translation to Arabic were done, and sample not realized in the main sample.

\section{Ethical Considerations}

Before conducting the study, explanation of the nature and aim of the study have been explained to staff nurses included in the subject were informed that participation in the study is voluntary and informal consent was obtained from each participant in the study. Confidentiality of data obtained was protected by the allocation of a code number to the questionnaire sheets. Subjects were informed that the content of the tools will be used for the research purpose only. Participants' right to withdraw from the study at any time was ascertained.

\section{Procedure}

Aletter was submitted from the dean of faculty of nursing in Benha University to the administrator of benha university hospital explaining the purpose and method of data collection. Data collection took about three months from beginning of July / 2o17 to beginning of August /2o17 for three days peer a week. The researcher met staff nurses and head nurses and explained the aim and the nature of the study and the method of filling questionnaire. The researcher distributed the questionnaire sheets to the participated staff nurses to fill it in work times which determined before with them.

\section{Results}

The study findings were presented in four different parts as follow:-

Part (I): Personal characteristics of nursing personnel. (table1,figure 1).

Table (1): Indicates distribution of study sample according to their personal characteristics, the results revealed that the majority of both staff nurses and head nurses $(91 \%, 92,3 \%)$ respectively were female. Regarding to age, the highest percent of both staff nurses and head nurses , $(49,5 \%, 46,2 \%)$ respectively had age From 2o to less than 29 years. According to marital status, the most of staff nurses $(82,1 \%)$ were married, also the majority of head nurses $(92,3 \%)$ were married. Regarding to educational qualifications more than half of staff nurses $(52,6 \%)$ had bachelor degree of nursing and $(69.5 \%)$ of head nurses had bachelor degree of nursing. concerning years of experience, the highest percent of both staff nurses and head nurses $(32.4 \%, 30,8 \%)$ respectively had from 1 to less than 5 years of experience.

Figure (1): Shows the distribution of the sample according to their department, it was noticed that $(38,6 \%)$ represent for Icu unit followed by dialysis, Icu , gynecology reception, medical reception, end by orthopedic, pediatric reception $(6,9 \%)$.

Part (II): Nursing personnel perception toward role of triage nurse in emergency department. (Table 2-6, figure 2-7).

Figure (2): Shows that the most of both head nurses and staff nurses $(84.6 \%$, $84.1 \%$ ) respectively had a high perception level toward role of triage nurse in emergency department.

Part (III): Nursing personnel readiness toward role of triage nurse in emergency department/unit. (Table 7-8 rfigure 810).

Figure (3): Illustrates that all head nurses had a high readiness level toward role of triage nurse in emergency department, and also the majority of staff nurses $(95,2 \%)$ had a high readiness level toward role of triage nurse in emergency department.

Figure (4): Demonstrates that all head nurses had a high readiness level toward skills required for triage nurse, and the majority (97\%) of staff nurses also had a high readiness level toward skills required for triage nurse. 


\section{Nursing Personnel Perception and Readiness toward Role of Triage Nurse in Emergency Department}

Figure (5): Shows that all head nurses had a high readiness level toward actions taken by triage nurse and the majority of staff nurses $(97,2 \%)$ also had high readiness level toward actions taken by triage nurse.

Part (IV): Correlation between perception and readiness of nursing personnel toward role of triage nurse in emergency department (table 9).

Table (9): Demonstrates that there was a highly statistically significant positive correlation between nursing personnel perception and readiness toward role of triage nurse in emergency department.

\section{Part (I) Personal characteristics of nursing personnel.}

Table (1): Frequency Distribution of Study Sample according to their Personal Characteristics $(\mathrm{N}=158)$.

\begin{tabular}{|c|c|c|c|c|}
\hline \multirow{2}{*}{ Personal characteristics items } & \multicolumn{2}{|c|}{ Staff nurses $(n=145)$} & \multicolumn{2}{|c|}{ Head nurses $(n=13)$} \\
\hline & No & $\%$ & No & $\%$ \\
\hline \multicolumn{5}{|l|}{ Sex } \\
\hline Male & 13 & 9.0 & 1 & 7.7 \\
\hline Female & 132 & 91.0 & 12 & 92.3 \\
\hline \multicolumn{5}{|l|}{ Age } \\
\hline $20<29$ year & 72 & 49.6 & 6 & 46.2 \\
\hline $29<39$ year & 59 & 40.7 & 5 & 38.5 \\
\hline$\geq 39$ year & 14 & 9.7 & 2 & 15.4 \\
\hline Mean \pm SD & \multicolumn{2}{|c|}{$31.7 \mathrm{o} \pm 6.15$} & \multicolumn{2}{|c|}{$33.15 \pm 6.81$} \\
\hline \multicolumn{5}{|l|}{ marital status } \\
\hline Married & 119 & 82.1 & 12 & 92.3 \\
\hline Un married & 26 & 17.9 & 1 & 7.7 \\
\hline \multicolumn{5}{|l|}{ Educational qualification } \\
\hline Technical diploma in nursing & 31 & 21.4 & - & - \\
\hline Technical institute of nursing & 29 & 20.0 & 4 & 30.8 \\
\hline Bachelor degree of nursing & 79 & 52.6 & 9 & 69.2 \\
\hline Diploma specialized & 6 & 3.8 & - & - \\
\hline \multicolumn{5}{|l|}{ years of experience } \\
\hline$<5$ years & 47 & 32.4 & 4 & 30.8 \\
\hline $5<10$ years & 42 & 29.0 & 3 & 23.1 \\
\hline $10<20$ years & 40 & 27.6 & 4 & 20.8 \\
\hline$\geq 20$ year & 16 & 11.0 & 2 & 25.4 \\
\hline Mean \pm SD & \multicolumn{2}{|c|}{$10.04 \pm 6.82$} & \multicolumn{2}{|c|}{$11.30 \pm 7.55$} \\
\hline
\end{tabular}

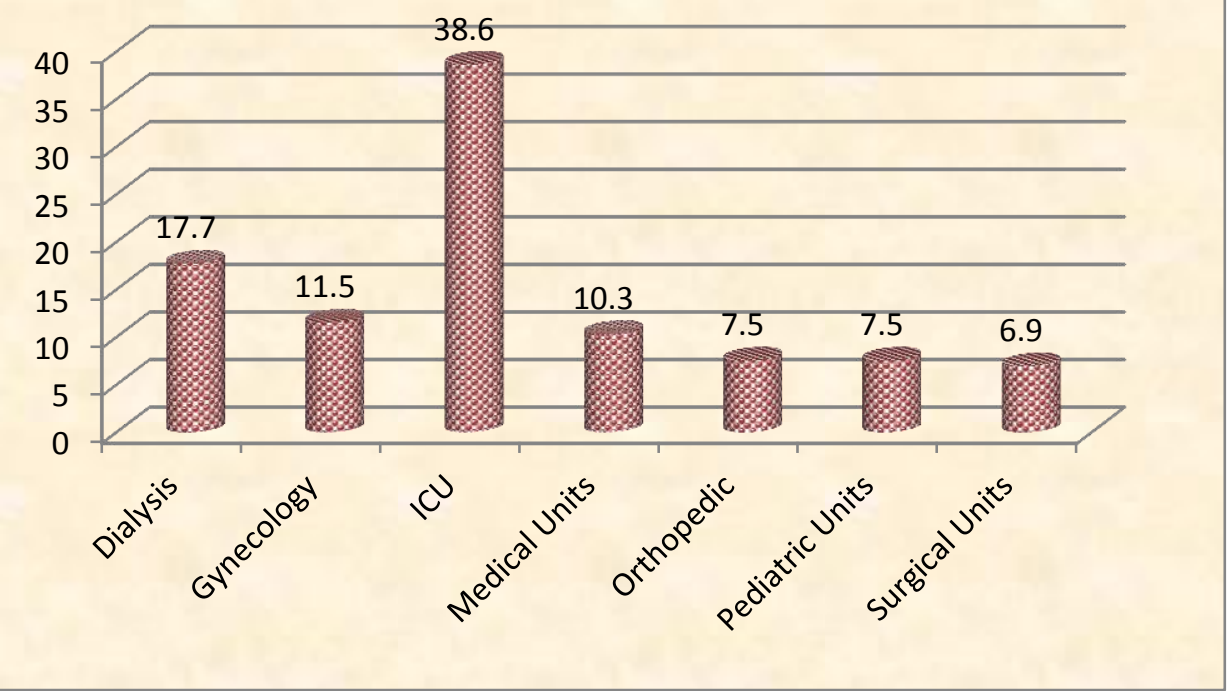


Nursing Personnel Perception and Readiness toward Role of Triage Nurse in Emergency Department

Figure (1): Frequency Distribution of Study Sample according to their Work Department/units.

Part (II) Nursing Personnel Perception Toward Role of Triage Nurse in Emergency Department.

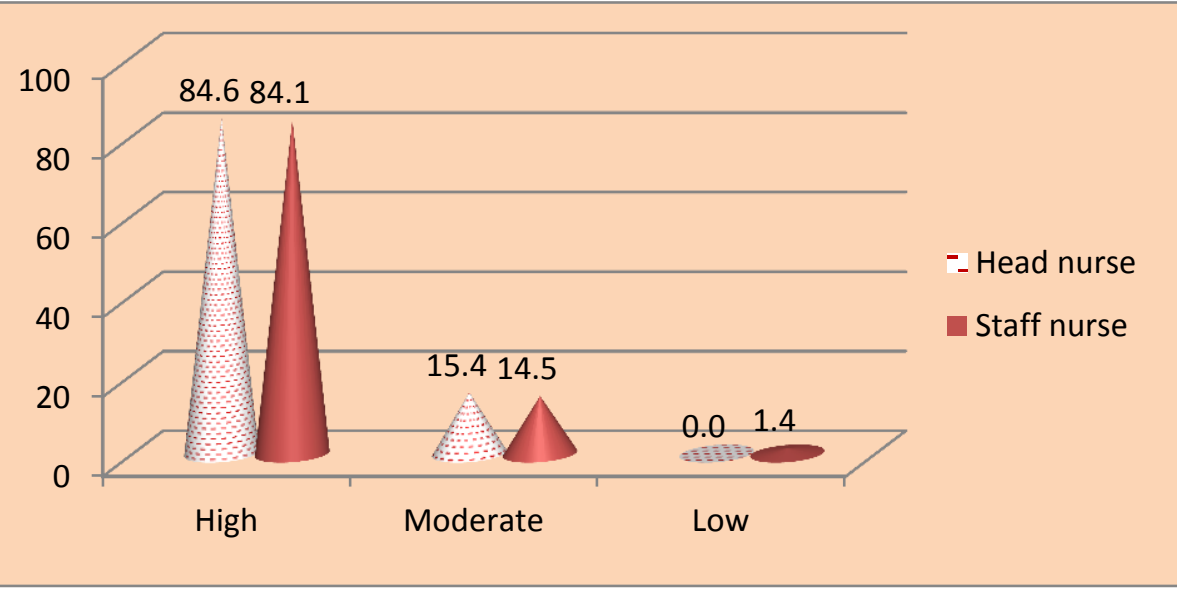

Figure (2): Distribution of Nursing Personnel according to their level of Perception toward Role of Triage Nurse in Emergency Departments.

Part (III):Nursing Personnel Readiness toward Role of Triage Nurse in Emergency Departments/units

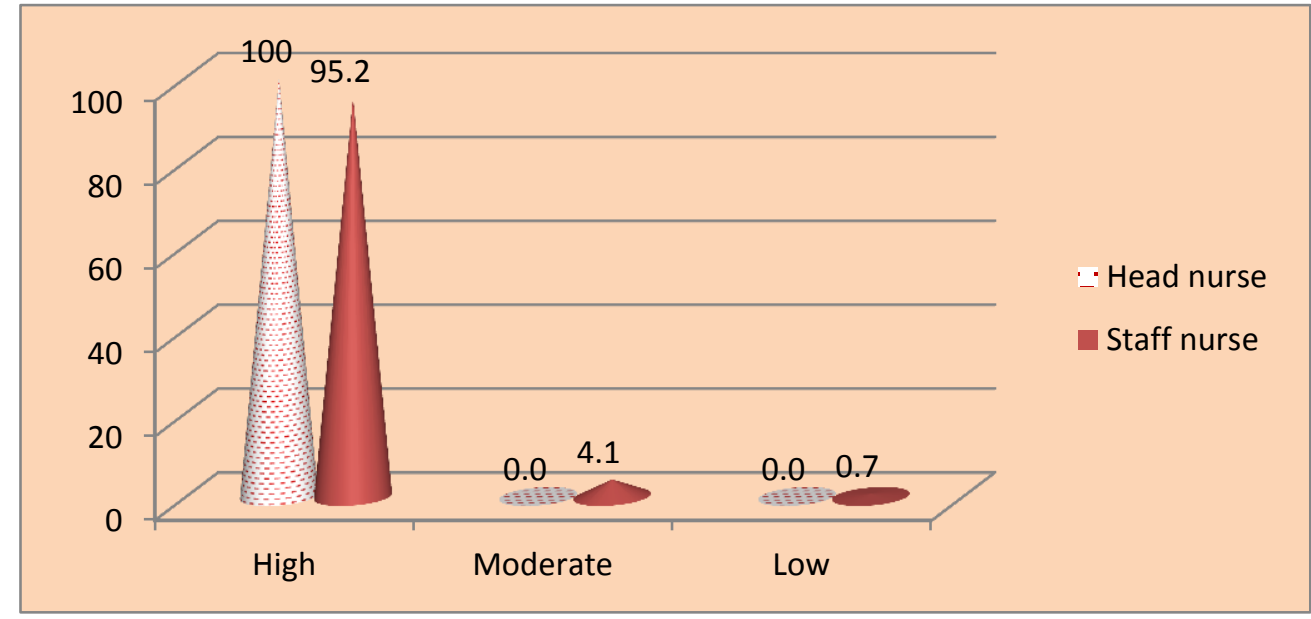

Figure (3): Distribution of Nursing Personnel According to their Level of Readiness toward Role of Triage Nurse in Emergency Departments.

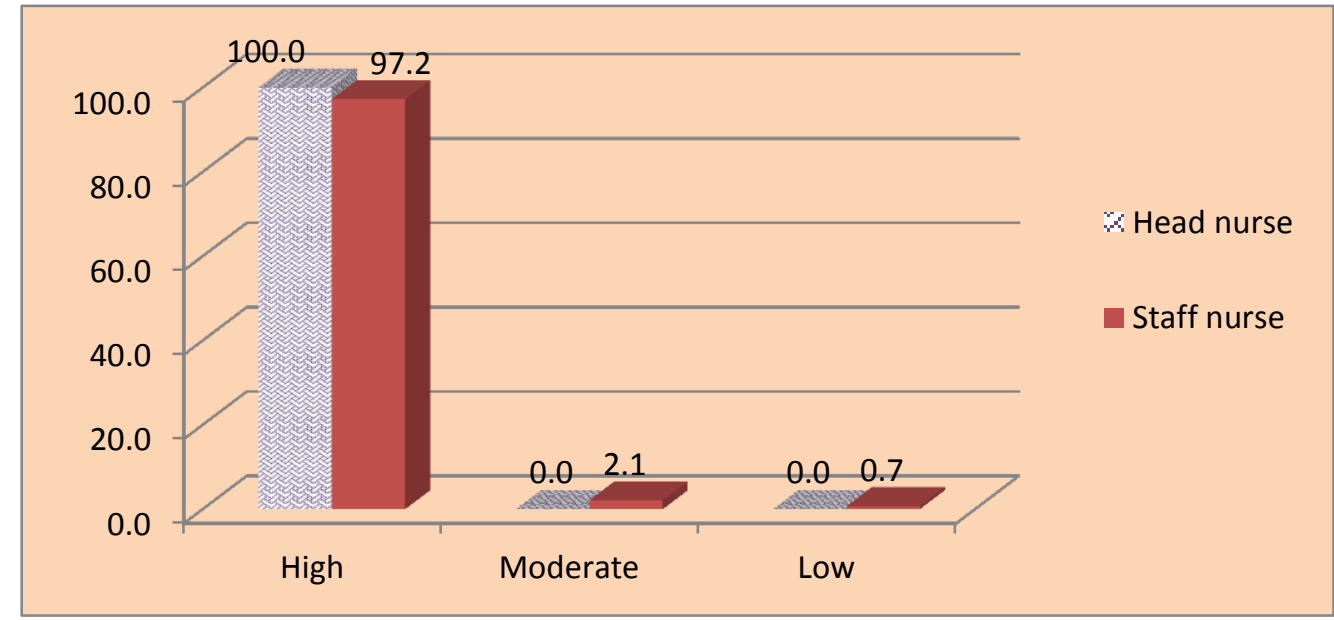


Figure (4): Nursing Personnel Readiness Level Regarding Skills Required for Triage Nurse $(\mathbf{N}=158)$.

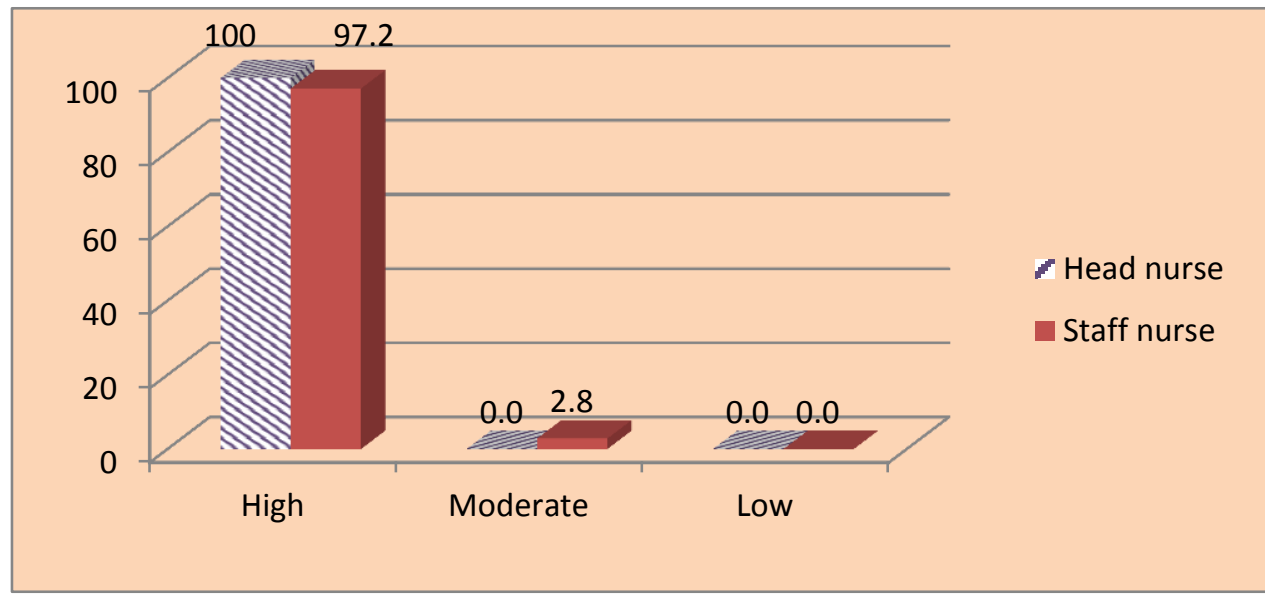

Figure (5): Nursing personnel Readiness Levels Regarding Actions Taken by Triage Nurse $(\mathbf{N}=158)$.

Part (IV): Correlation Between Total Perception Scores and Total Readiness Scores of Nursing Personnel Toward Role of Triage Nurse in Emergency Departments/units(N=158).

Table (9): Correlation Between Total Perception Scores and Total Readiness Scores of Nursing Personnel Toward Role of Triage Nurse in Emergency Departments/units(N=158).

\begin{tabular}{|l|c|c|c|c|}
\hline \multirow{2}{*}{ Variable } & \multicolumn{4}{|c|}{ Total perception scores } \\
& \multicolumn{4}{|c||}{ Staff nurses } \\
\cline { 2 - 5 } & Head nurses & p-value & $\mathrm{R}$ & p-value \\
\cline { 2 - 5 } & $\mathrm{R}$ & $0.000^{*} *$ & 0.49 & $0.000^{* * *}$ \\
\hline Total readiness score & 0.38 & & \multicolumn{3}{|c|}{0.49} \\
\hline
\end{tabular}

\section{Discussion}

This study was conducted to identify nursing personnel perception and readiness toward role of triage nurse in emergency department at Benha University Hospital.

This study covered four main areas, firstly: personal characteristics of nursing personnel, secondly: nursing personnel perception toward role of triage nurse in emergency department, thirdly: nursing personnel readiness toward role of triage nurse in emergency department, fourthly: correlation between perception and readiness of nursing personnel toward role of triage nurse in emergency department.

\section{Nursing personnel perception toward role of triage nurse in emergency department.}

According to the study findings; most of both head nurses and staff nurses had high perception level toward role of triage nurse in emergency department. From the investigator point view this result due to patient who enters emergency departments and critical units is usually a critical case and need specialized care then nursing personal in this study already perform the role of triage nurse and apply triage process without knowing that the role of triage nurse. In addition, the highest percent of them 


\section{Nursing Personnel Perception and Readiness toward Role of Triage Nurse in Emergency Department}

had bachelor degree in nursing which enable them to study know what to do for emergency patients.

In relation to nursing personnel readiness toward role of triage nurse in emergency department.

According to the study findings, all head nurses had high readiness level toward role of triage nurse in emergency department, and the majority of staff nurses also had high readiness level toward role of triage nurse in emergency department. From the investigator point view, this might be due to staff nurses and head nurses had knowledge and experience that enable them to perform the role of triage nurse and they perform the role of triage nurse without know that is the role of triage nurse.

Concerning Correlation between perception and readiness of nursing personnel toward role of triage nurse in emergency department

Regarding the correlation between perception and readiness of nursing personnel toward role of triage nurse in emergency departments. The results of the present study demonstrates that there was a highly statistically significant positive correlation between nursing personnel perception and readiness of nursing personnel toward role of triage nurse in emergency department. The result of the present study demonstrated result due to both staff nurses and had nurses who work in emergency departments and critical units have knowledge and qualifications that enable them to be applicator for the role of triage nurse in emergency departments.

\section{Conclusion}

The present study was conducted to identify nursing personnel perception and readiness toward role of triage nurse in emergency department at
Benha University Hospitals. It is concluded that most of both head nurses and staff nurse had a high perception level toward role of triage nurse in emergency department and all head nurses had a high readiness level toward role of triage nurse in emergency department, and also the majority of staff nurses had high readiness level toward role of triage nurse in emergency department. Moreover, that there was a highly statistically significant positive correlation between perception and readiness of nursing personnel toward role of triage nurse in emergency department.

\section{Recommendations:}

In the lights of the findings obtained from the present study these points are recommended:

\section{At nursing level:}

1) Designing and implementing triage system in Benha University Hospitals to improve outcomes and enhances patients' satisfaction.

2) Implementing patient's rights regulations.

3) Providing an educational program for nursing personnel about cultural diversity for patients.

At educational level:

1) Providing regular in-service training programs to emergency health care team regarding the triage to draw attention on nurse role, qualifications, preparation and triage process.

2) Conducting training nursing personnel how to perform and interpret ECG, especially.

3) Conducting training disaster sinario as role play.

\section{Future researches are suggested}

1) Exploring factors that facilitate implementation of triage on call.

2) Designing guide-lines about role of triage nurse in emergency 
department.

3) Implementing a triage system in Governmental and nonGovernmental hospitals.

\section{References}

Welch, S,. Asplin, B,R., Griffith ,S., Davidson, S.,J., Augustine, J. and, Schuur, J. (2o11): Emergency Department Operational Metrics, Measures and Definitions: Results of the Second Performance Measures and Benchmarking Summit. Annals of Emergency Medicine Journal, 58(1),33-40.

Margaret, F. (2o17): Accident and Emergency Nursing, An Educational Frame work for Triage Nursing based on Gate keeping, time keeping and Decision -Making processes Journal, 13(4), 214-219.
Mayckel, B. (2015):Perception of The Nursing Staff About The Nurse's Role in The Emergency Service, Revistarene Journal, 16(6) ,833-841

Leanne, A., Andrea, M. and Wendy, C. (2o16): Critical Care Nursing, $3^{\text {rd }}$ ed,

Australian college of Critical care Nurses, China, Pp737-740

Hirnie, J. (2013): Fundamentals of Nursing, $2^{\text {nd }}$ ed, Lippencott, Raven, Pp 52-59

Elhabashy,S. (2015): Cardio Thoracic Injury, Essentials all Critical Care Nurses Need to Know, $1^{\text {st }}$ ed, Mosby Elsevier, USA, Pp 710.

Biddle, J. (2014): Recent Development in Role Theory, $2^{\text {nd }}$ ed, Annual Review of Sociology, India, Pp 1267-1292. 